\title{
Regionalização do Cuidado em Saúde Mental: Humanização da Assistência na Perspectiva do Serviço de Saúde em Rede
}

\author{
Cabral, Mariana Pompílio Gomes; Jorge, Maria Salete Bessa; Maia Neto, José Pereira; \\ Costa, Juliana Pessoa; Aragão, Patrícia Frota; Caminha, Emília C. Carvalho Rocha
}

Universidade Estadual do Ceará — mari.pompilio@gmail.com

Introdução: a Política Nacional de Humanização preconiza, como um dos princípios básicos, o serviço assistencial à saúde em rede com alta conectividade, de modo cooperativo e solidário, em conformidade com as diretrizes do SUS. Isso pressupõe a articulação e a transversalidade do cuidado integral ao usuário do serviço de saúde nos três principais pontos da rede: atenção primária, especializada e terciária. em relação à atenção especializada da rede de assistência à saúde mental, tem-se a necessidade de construir uma assistência que privilegie serviços de atenção psicossocial, com base nas dimensões comunitárias, territoriais e na aproximação ética, social e solidária entre profissionais e usuários, em busca de articular os vários dispositivos da região de saúde. Objetivo: Compreender o processo de regionalização em saúde na perspectiva da humanização do cuidado ao usuário de saúde mental. Metodologia: o estudo faz parte de uma pesquisa ampla denominada "Organização da rede regional de saúde e sua interface com a saúde mental no estado do ceará: dimensão política, econômica, social, organizacional, tecnológica e simbólica", com financiamento do CNPq/MS. Trata-se de uma pesquisa qualitativa, crítica e reflexiva, realizada com trabalhadores da ESF e do CAPS, bem como usuários em tratamento nos municípios de Fortaleza e Eusébio. para a coleta de dados utilizou-se a entrevista semi-estruturada e a análise dos dados seguiu a orientação da Análise de Conteúdo. o estudo foi aprovado pelo Comitê de Ética em Pesquisa (CEP) da Universidade Estadual do Ceará (UECE). Resultados: do processo de regionalização, destaca-se a importância da atenção primária no cuidado aos usuários de saúde mental, reconhecendo - os em seus territórios e em suas condições biopsicossociais e, só a partir disso, propor promoção e prevenção de saúde, além de encaminhamentos desses usuários ao Caps ou outros serviços da rede social de apoio. para os profissionais, a assistência regionalizada permite que as equipes de saúde conheçam a realidade do usuário em seu cotidiano comunitário, sendo esta, uma condição fundamental para planejar, encaminhar ou resolver a situação demandadas naquele serviço. Já os usuários consideram que o acesso está ampliado. Se antes eles só conheciam o hospital mental em forma de emergência agora percebem que saúde mental está imbricada à saúde básica e secundária. Conclusão: Aponta-se, como égide da temática, a importância do serviço de saúde em rede como fomentador e facilitador de um cuidado embasado no conhecimento das dimensões sócio-espaciais e antropológicas dos usuários, se aproximando de uma assistência humanizada e se distanciando, cada vez mais, do modelo de assistência à saúde mental isolada, excludente de direito, desumana e violenta, muito demarcada na história da saúde mental.

Cabral, Mariana Pompílio Gomes; Jorge, Maria Salete Bessa; Maia Neto, José Pereira; Costa, Juliana Pessoa; Aragão, Patrícia Frota; Caminha, Emília C. Carvalho Rocha. Regionalização do Cuidado em Saúde Mental: Humanização da Assistência na Perspectiva do Serviço de Saúde em Rede. In: Anais do Congresso Internacional de Humanidades \& Humanização em Saúde [= Blucher Medical Proceedings, num.2, vol.1]. São Paulo: Editora Blucher, 2014. ISSN 2357-7282

DOI 10.5151/medpro-cihhs-10809 